\title{
THE EVALUATION OF THE COFFEE MARKET UNDER THE APPLICATION OF THE COFFEECONOMICS INDEX
}

Keywords:

Coffee, Guatemala, coffee market structure, economics research, Econographicology

$\underline{\text { JEL code }}$

B40

\author{
First-Author \\ Dr. Mario Arturo Ruiz Estrada \\ Social Wellbeing Research Centre (SWRC), \\ University of Malaya (UM), \\ Kuala Lumpur 50603, Malaysia \\ [E-mail] marioruiz@um.edu.my
}

\author{
$\underline{\text { Second-Author }}$ \\ Peter Moug, \\ School of Politics, History, and International Relations, \\ Faculty of Social Sciences, \\ The University of Nottingham (Malaysia Campus) \\ Selangor 43500, Malaysia. \\ [E-mail] Peter.Moug@nottingham.edu.my
}

\author{
Third-Author \\ Rashid Ating \\ Social Wellbeing Research Centre (SWRC), \\ University of Malaya (UM), \\ Kuala Lumpur 50603, Malaysia \\ [E-mail] rashid_ating@um.edu.my
}




\begin{abstract}
$\underline{\text { Abstract }}$
The Coffeeconomics index is an alternative index to evaluate the Coffee market structure behaviour from a microeconomic and macroeconomic perspective. Hence, the coffee market structure is formed by the interaction of four large players such as coffee producers (small, cooperatives, and large), coffee brokers, coffee sellers (large, medium, and small), and coffee consumers. The main objective is to evaluate the vulnerabilities of the coffee market structure as a whole through the application of the National Coffee Production Function (NCP-Function). Finally, we calculate the NCP-Function to evaluate the risk and vulnerability of the coffee market structure of Guatemala between 1928 and 2018 respectively.
\end{abstract}

\title{
1. A General Brief of Coffee
}

The long history of coffee dates back from Ethiopia (Africa). Hence, the coffee had a long history with different transcendental events from the 15th Century. This long history of coffee involves a dynamic transformation in the production, trading, and consumption of coffee until nowadays. The history of coffee trading can be divided into three large periods include: (i) Coffee arrives from Ethiopia to Middle East (Arabian Peninsula) in the 15th century; (ii) from the Arabian Peninsula started the trading of coffee to Europe in the 17th century; (iii) Finally, the production and trading of coffee moves from Europe to America in the 18th Century. The mechanism was applied for all Europeans empires in the production and trading of coffee in different parts of America, it was based on the invasion of new territories policy (conquered colonies) through the uses of force, violence, and repression to native people and exploitation of its natural resources. The most powerful and largest European empires from 17th to 18th Century was the British, Spanish, Portuguese, French, and Dutch empires. The production of coffee in America was based on the uses of large coffee plantations together with uses of intensive slave's labour (from Africa and aborigine people) for many centuries. The conquered colonies to produce coffee in America, Asia, and Africa by Europeans empires were divided into North America (South part of Mexico under the control of the Spanish empire domination), Central America (Guatemala, El Salvador, Honduras, Nicaragua, and Costa Rica under the control of the Spanish empire domination), Caribbean (Jamaica -British empire-, Haiti -French empire-, and Trinidad Tobago -British empire domination-), South East Asia (Vietnam -French empire domination -, Indonesia -Dutch empire domination -, Laos -French empire domination-, and Papua New Guinea -British and Dutch empire domination), India (British empire domination), and South America (Colombia, Brazil, Peru, Ecuador, and Bolivia under the control of the Spanish empire domination) respectively.

However, the fast global expansion of the coffee market in different places around the world requests a deeper evaluation of four main player's behaviour such as the producers, brokers, sellers, and consumers (buyers) as a whole. According to this research paper, the interaction of those main four players in the coffee market structure requests a special 
mechanism of evaluation. It is based on the creation of different indicators and analytical tools to evaluate the risk and performance of the coffee market structure respectively.

The first players in the coffee market structure are the coffee producers. This research found a list of the top producers of coffee by continent, countries, and percentage of participation in the worldwide coffee production. those are followed by the American Continent with 59\% (Brazil, Colombia, Mexico, Honduras, Guatemala, Peru, Nicaragua, Costa Rica, El Salvador, Ecuador, Venezuela, Dominic Republican, Haiti, Cuba, Panama, Bolivia, Puerto Rico, Paraguay, and Trinidad and Tobago); Asia with 25\% (Vietnam, Indonesia, India, Laos, Thailand, Philippines, Timor Leste); Africa with 15\% (Ethiopia, Uganda, Ivory Coast, Kenya, Tanzania, Cameroon, Madagascar, Gabon, Democratic Republic of Congo, Rwanda, Burundi, Togo, Nigeria, Ghana, Sierra Leone, Angola, Zimbabwe, Liberia); Oceania with 1\% (Australia and New Zealand). In fact, the top ten players of coffee producers worldwide follow this order: Brazil, Vietnam, Colombia, Indonesia, Ethiopia, Honduras, India, Uganda, Mexico, and Guatemala.

This research also found that exist two large types of coffees in production such as Robusta (stronger taste and harsher taste) and Arabica (sweeter and softer taste). According to different statistical sources from ICO, these two types of coffees in production is distributed in Arabica $(60 \%)$ and Robusta $(40 \%)$ worldwide. Also, this research makes reference to the classification of the genus Coffea (coffee beans) species are divided into three large groups: Arabica, Dewevrei, and Stenophylla respectively (Seudieu, 2008). Another main point of discussion in this section, it is about the special conditions are requested in the production of coffee: (i) the location of major producers of coffee is in the equatorial belt; (ii) the coffee is very vulnerable to climate change, weather and natural disasters; (iii) the production of coffee requests an optimum temperature between $64^{\circ} \mathrm{F}$ and $72^{\circ} \mathrm{F}$.

All these factors make possible to evaluate the high vulnerability of coffee producers. In addition, we found that the profit of coffee producers can get from coffee brokers is between $15 \%$ and $20 \%$ in a good harvest. Some recent statistics from ICO shows how many producers suffer large losses and bankruptcy. The large losses are originated from fast climate change, unpredicted weathers changes, and disease (fungal, parasitic, viral, disorders). At the same time, if the largest losses of coffee producers can lead to reducing the supply then the coffee brokers profit margin must be smaller than the profit margin predicted. Also, the structure of producers of coffee has itself specific sizes respectively such as large producers, cooperatives, and small producers.

According to recent statistics from ICO, the producers share the next percentage of participation in the production of coffee followed by large producers (55\% of total worldwide production of coffee), cooperatives ( $31 \%$ of total worldwide production of coffee), and small producers of coffee ( $14 \%$ of total worldwide production of coffee). Therefore, the margins of profits are directly connected with the size of the producer. The large producers are getting a 
large margin of profits and subsequently in small amounts the small producers of coffee respectively.

The second main player in the coffee market structure is the brokers of coffee. They are going to playing a crucial role in the worldwide price of coffee. According to this research, the price of coffee always raises considerably in this stage of commercialization between the producer and broker of coffee. Always exist a high possibility of constant speculation and high risk because they are pushing for lower prices from the producers and get a high price from the sellers. The main role of brokers is focused to be the link between producers and sellers. This research found that the brokers of coffee can earn a profit ratio between $25 \%$ and $35 \%$ in the final selling.

The third main player in the coffee market structure is the coffee sellers (large, medium, and small). The main role of the coffee sellers in the coffee market structure is to fix the final price for whole coffee consumers in any market. The margin of profit of sellers is between $15 \%$ to $25 \%$ in good sells seasons. The high success of coffee sellers depends highly on the good quality of coffee, brokers prices, marketing strategies, channels of distribution (domestic and internationally), diversity and creativity of new drinks related to coffee, and good customer service. The sellers always are going to playing an important role to keep the demand for coffee active and sustainable in the short a long run. According to this research, the large sellers share $62 \%$ of the worldwide coffee market, those large sellers of the coffee list is followed by Starbucks, Coffee Bean, Gloria Jeans Coffee, Caribou Coffee, Dunkin' Donuts, McCafe (McDonald's), Tully's Coffee, Costa Coffee, Lavazza Coffee, and Nestle. In the case of a medium coffee, sellers cover only $28 \%$ of the coffee market worldwide. Subsequently, the small coffee sellers only keep $10 \%$ of the total worldwide coffee.

The last but not least, the fourth player in the coffee market structure is the consumers of coffee. Basically, we found that the consumption of coffee is directly connected to five main factors: (i) the fast expansion of the income-per-capita (economic growth); (ii) accessible prices between coffee producers and coffee brokers; (iii) young coffee consumers (new ways to attract new potential buyers of coffee); (iv) the faster changes in the preference and taste of the consumers of coffee worldwide (especially in the Chinese market and Asian markets); (v) a strong and sustainable marketing strategy from sellers to consumers of coffee. According to recent statics, the consumption of coffee is growing geometrically exponential in $35 \%$ per year from the year 2001. This increment in the consumption of coffee has its origins from the incorporation of China in the World Trade Organization officially (WTO, 2018). Additionally, some markets in Asia is increasing considerably the consumption of coffee such as the case of Malaysia (the growth rate of consumers of coffee moves in $23 \%$ annually), Singapore (the growth rate of consumers of coffee is growing constantly by $35 \%$ annually), Indonesia (the growth rate of consumers of coffee expand to $27 \%$ annually), Thailand (the annual growth rate of consumers of coffee is equal to $23 \%$ ), Taiwan (the annual growth rate of consumers of coffee arrives at $15 \%$ ), South Korea (the annual growth rate of consumers of coffee is equal to $33 \%$ ), 
Japan (the annual growth rate of consumers of coffee keeps a value of $21 \%$ ), and Philippines (the annual growth rate of consumers of coffee arrives in only $12 \%$ ).

\section{An Introduction to The Coffeeconomics Index}

"the Coffeeconomics index" can be defined as "a new index that is in charge in evaluating any issue related to the coffee market structure through the exhausted research of producers, brokers, sellers, and consumers of coffee behaviour together as a whole in the short and long run. The Coffeeconomics index is supported by the use of different quantitative research tools as well as qualitative research tools to analytically evaluate the truthfulness and reliability of different coffee markets around the world, anywhere and anytime."

As an integral part of this definition, "Coffee Market Structure" is defined as "the dynamic interaction of four large players follow by producers, brokers, sellers, and consumers that searching for different benefits (or surplus) in the coffee trading process (From a large profit to a maximum consumer satisfaction). Hence, we assume that the coffee market structure always is going to keeps failures and a dynamic imbalance state (DIS) (Ruiz Estrada, 2013) under the application of Omnia Mobilis Assumption (Ruiz Estrada, 2011)."

The main objective of the Coffeeconomics index is to generate a specific economic research field to evaluate qualitatively and quantitatively the coffee market structure and all different players from an economic point of view were hardly in the past. Therefore, the study of the coffee structure involves a serial of difficulties such as (i) the limited information from producers; (ii) high speculation especially from brokers and sellers; (iii) income inequality and preference of coffee consumers.

The fast expansion in the consumption of coffee worldwide makes essential to generate the Coffeeconomics index. According to statistics from the World Trade Organization (WTO, 2017), the consumption from 1999 to 2019 increased to $21 \%$ (After Chine access to WTO). In fact, the coffee opens a new opportunity to producers and consumers to get large benefits in the short and long run. Moreover, the main problem became more complex nowadays in getting easy access to the coffee market prices database and documents. However, we also can observe that many information about coffee is limited. Additionally, the high speculation and unknown distribution channels make impossible to get the trading routes and prices (price negotiation between producers and brokers). The speculation of coffee prices is generating inconsistency to elaborate trustable economic research to evaluate the coffee market structure problems. Going forward, we look for possible future evolutions in the collection of coffee cost and prices database and documents access. Possible future face three key challenges: (i) searching of primary data from producers cost (large and small coffee country producers); (ii) the monitoring of coffee brokers around the world; and (iii) monitoring prices and quality of coffee between sellers and consumers of coffee. The future of the coffee market structure highly depends to follow its microeconomic and macroeconomic behaviour in the short and long run. 
At the same time, the Coffeeconomics index is interested to follow all new technologies and innovative products and services from this large specific industry of coffee.

The primary objective of the Coffeeconomics index involves to evaluate and generate policies to benefit in general all players in the coffee market structure together through the generation of specializing research to evaluate possible scenarios under varying levels of risk to evaluate possible policies to solve any problem in the coffee market structure. The main challenge of the Coffeeconomics index is to moving from the traditional cost-benefit modelling to more dynamic and applicable economic simulations to follow closely the coffee market structure behaviour. The second challenge in the Coffeeconomics index is to use artificial intelligence (AI), also known as the neural networks approach. The uses of AI can help to evaluate the four main players in the coffee market structure behaviour such as producers, brokers, sellers, and consumers of coffee simultaneously. The neural networks provide a powerful analytical tool to evaluate cost, prices, technological change, markets trend of coffee. The primary objective of neural networks is to choose among a large cost, prices, technological change, markets trend of coffee database and documents, as well as the most suitable possible solutions in the coffee market structure failures anytime and anywhere.

Therefore, the adaptation of AI to solve coffee market structure failures is directly connected to new mathematical modelling such as the chaos theory, logical mathematics, and neural networks. Finally, we are interested to introduce a new simulator to evaluate coffee market structure failures. This new simulator is entitled "The National Coffee Production Function (NCP-Function)." The next section is going to give a detailed explanation of the NCP-Function respectively.

\section{Introduction to The National Coffee Production Function (NCP-Function)}

The National Coffee Production Function (NCP-Function) will be explained by this section of our paper. Initially, the NCP-Function is built by four sub-production functions: (1.) Coffee Producers; (2.) Coffee Brokers; (3.) Coffee Sellers; (4.) Coffee Consumers. Each subproduction function has its quadrant respectively. Each quadrant shows a single dependent variable represented by a vertical line the in the centre part of its quadrant by $\beta_{\mathrm{ij}}$ and " $n$ " number of independent variables $\alpha_{\mathrm{ij}}$ on the bottom part of the quadrant by horizontal lines. Finally, we join all $\alpha \mathrm{ji}$ to the dependent variable $\beta_{\mathrm{ij}}$ under the application of " $"$ " linkage of axes. All axes in each quadrant are running on real-time under the application of dynamic growth rates (See Expression 1.5). Therefore, we have four quadrants or four sub-production functions, each quadrant has its dependent variable " $\beta_{\mathrm{ij}}$ " by " $n$ " number of independent variables " $\alpha_{\mathrm{ij}}$ " respectively. In our case, we have four outputs from producers $\left(\beta_{0}\right)$, brokers $\left(\beta_{1}\right)$, Sellers $\left(\beta_{2}\right)$ and consumers $\left(\beta_{3}\right)$ originated from each sub-production function. Finally, we can observe that among the four quadrants exist a single axis that we call the final coffee national output " $\beta$ " . It is based on joining the four outputs from each sub-production function by the application of the "占" linkage of quadrants by straight lines (See Figure 1), the idea is to build a single surface 
based on linking the four outputs from each sub-production function together in the same physical space.

In the NCP-Function objective is to build a large and single surface that is moving in real time in the same physical space. In fact, the application of the Omnia Mobilis assumption (Ruiz Estrada, 2011) is a basic condition to generate the real-time effect of the NP-Function. Hence, the final national output " $\beta$ " always keeps in dynamic and multi-dimensional behaviour according to the economic simulating (Ruiz Estrada, 2018) in real time into its multidimensional space. Finally, the analysis of the final result from the NCP-Function depends on the position of the surface can help to determinate the situation of an economy highly dependent on the coffee production, commercialization, and consumption performance. If the surface is located on a positive level, then we can observe coffee market stability. If the surface keeps on level zero, then we can observe a coffee market stagnation. If the surface keeps between negative and positive levels, then it is possible to observe a coffee market with high vulnerability. Finally, if the surface is located under the negative level then we find a coffee market in constant crisis (See Figure 1).

\subsection{The National Coffee Production Function Model}

The NCP-Function offers us an alternative graphical and mathematical modelling approach to analyze the final national output from a multi-dimensional perspective by country. In fact, the NCP-Function offer to policymakers, academics and central banks an alternative methodological approach to measure the final output of any country from the national coffee production function. The NCP-Function is built by four sub-production functions follow by:

Sub-Production Function 0: Coffee Producers

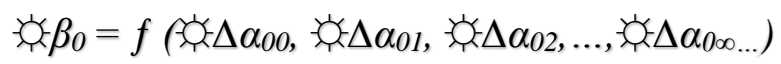

Sub-Production Function 1: Coffee Brokers

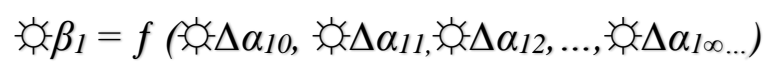

Sub-Production Function 2: Sellers

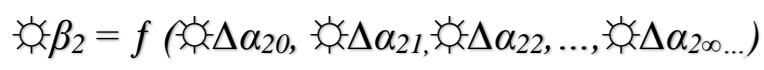

Sub-Production Function 3: Coffee Consumers

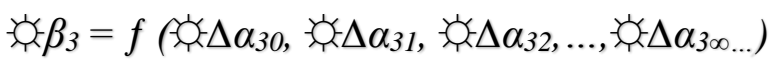

$$
\begin{aligned}
& \text { Real Time } \beta_{i}=\text { Output } \Delta=\text { Dynamic Growth Rate }
\end{aligned}
$$

All variables in each sub-production function request the application of the dynamic growth rate follow by:

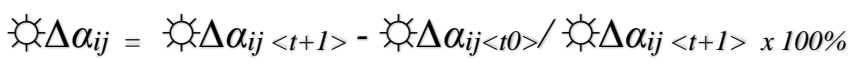

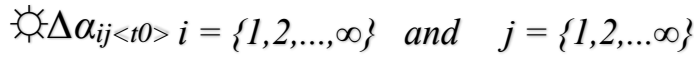




$$
<_{t+1}>=\text { Future period of time } \quad<_{t o}>=\text { Initial period of time }
$$

Therefore, the final mathematic structure to build the NCP-Function is based on expression (1.6.)

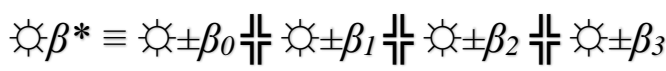

$$
\begin{aligned}
& \text { 㘳= linkage of quadrants }
\end{aligned}
$$

The Sub-Production Function 0 Specialization (Coffee Producer) shows a large number of factors and functions that affect its behaviour simultaneously according to Expression 7, 8, 9, and 10 respectively.

Sub-Production Function 0 - Coffee Producer " $A$ ”:

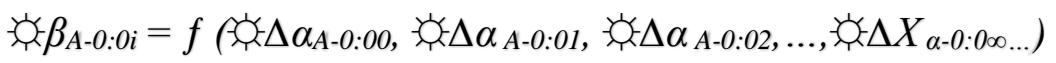

Sub-Production Function 0 - Coffee Producer "B":

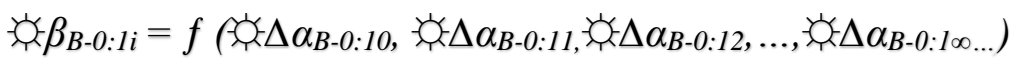

Sub-Production Function 0 - Coffee Producer " $C$ ".

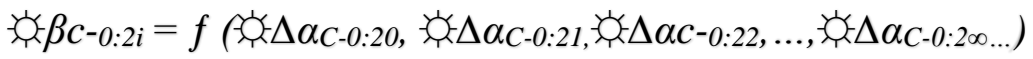

Sub-Production Function 0 - Coffee Producer " $Z$ ":

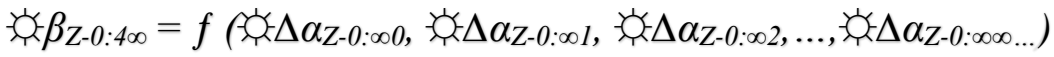

If any coffee producer in the same country displays the largest output from the sub-production

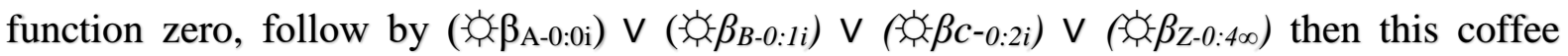
producer needs to be the main market price for the rest of coffee producers on the subproduction function zero.

Sub-Production Function 1 Specialization (Coffee Brokers) presents a large number of factors and functions that affect its behaviour simultaneously according to Expression 11, 12, 13 , and 14 respectively.

Sub-Production Function 1 - Coffee Brokers " $A$ ”:

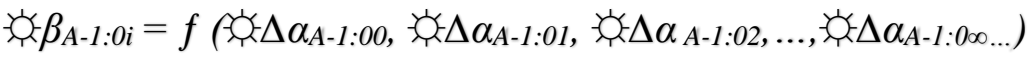

Sub-Production Function 1 - Coffee Brokers "B":

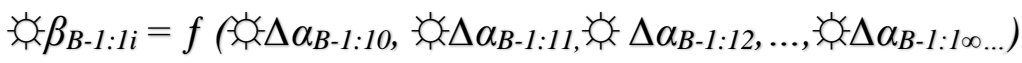

Sub-Production Function 1 - Coffee Brokers "C":

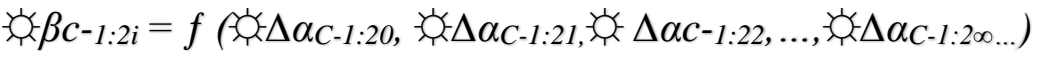

Sub-Production Function 1 - Coffee brokers " $Z$ ”: 
$=\beta_{Z-1: 400}=f\left(\begin{array}{c}\infty \\ -\infty\end{array} \alpha_{Z-1: \infty 0,}\right.$,

If any coffee broker from domestic or overseas display the largest output from the subproduction function one follows by $\left(\beta_{\mathrm{A}-1: 0 \mathrm{i}}\right) \vee\left(\beta_{B-1: 1 i}\right) \vee(1, \beta c-1: 2 i) \vee\left(\beta_{Z-1: 400}\right)$ then this coffee broker can find the best price on the sub-production function one.

Sub-Production Function 2 Specialization (Coffee Sellers) have a large number of factors and functions that affect the final price behaviour simultaneously according to Expression 15, 16,17 , and 18 respectively.

Sub-Production Function 2 - Coffee Sellers " $A$ ”:

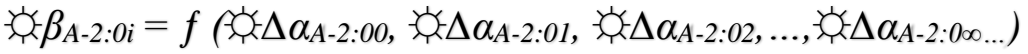

Sub-Production Function 2 - Coffee Sellers “B”:

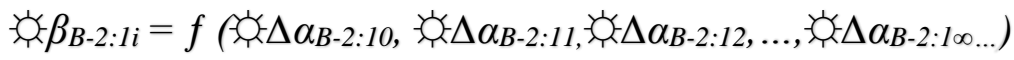

Sub-Production Function 2 - Coffee Sellers " C":

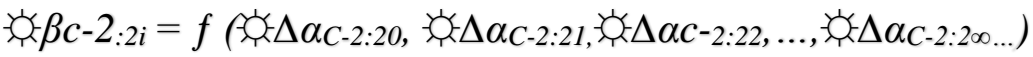

Sub-Production Function 2 - Coffee Sellers " Z":

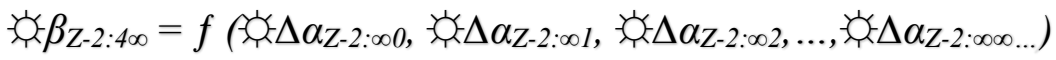

If any coffee seller in the same coffee market displays the largest output from the subproduction function two follow by $\left(\beta_{\mathrm{A}-2: 0 \mathrm{i}}\right) \vee\left(\beta_{B-2: 1 i}\right) \vee\left(\alpha^{\prime}-\beta c-2: 2 i\right) \vee\left(\beta_{Z-2: 400}\right)$ then this coffee seller can get the largest margin of profit on the sub-production function two.

Sub-Production Function 3 Specialization (Coffee Consumers) shows a large number of factors and functions that affect the final satisfaction of coffee consumer's behaviour simultaneously according to Expression 19, 20, 21, and 22 respectively.

Sub-Production Function 3 - Coffee Consumer " $A$ ":

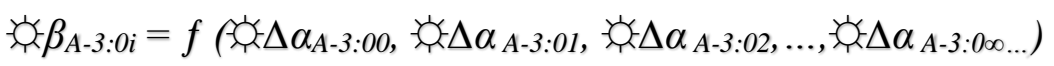

Sub-Production Function 3-Coffee Consumer "B":

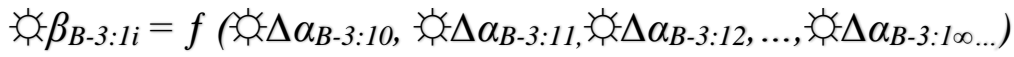

Sub-Production Function 3 - Coffee Consumer " C":

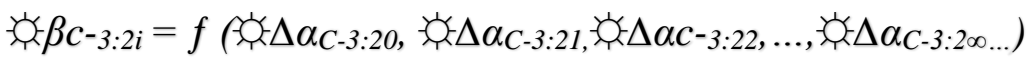

Sub-Production Function 3 - Coffee Consumer " $Z$ ":

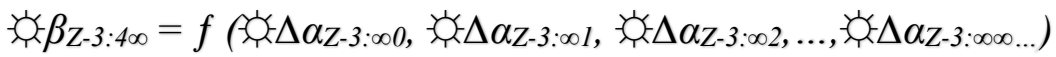


If any coffee consumer from the sub-production function three follows by ( $\left.\beta_{\mathrm{A}-3: 0 \mathrm{i}}\right) \vee\left(\beta_{B}\right.$ 3:1i $) \vee(-\alpha c-3: 2 i) \vee\left(-\beta_{Z-3: 400}\right)$ then this coffee consumer can get the best price, in our case, it is measured by the maximum coffee consumption satisfaction. The third step is to build the NCPFunction. It is based on joining all national coffee production functions outputs from producers, brokers, sellers, and consumers of coffee by straight lines until we can draw a single surface (See Figure 3). The NCP-Function is interested to verify the performance and effect before and after to implement of any coffee price among all coffee market actors such as producers, brokers, sellers, and consumers of coffee. The NCP-Function performance depends on the location of the surface. The location of this NCP-Function can show four possible results follow by the coffee market stability performance (See Expression 23), the coffee market stagnation performance (See Expression 24), the coffee market with high vulnerability performance (See Expression 25), and the coffee market in constant crisis performance (See Expression 26):

次 $\beta^{*} \equiv$

$\left\{\right.$ if $\Delta+\beta^{*} \cap \mathrm{R}_{+}$then the surface $\equiv$ the coffee market stability performance $\}$

婝 $\beta^{*} \equiv$

$\left\{\right.$ if $\Delta \mathrm{Y}^{*} \cap 0$ then the surface $\equiv$ the coffee market stagnation performance $\}$

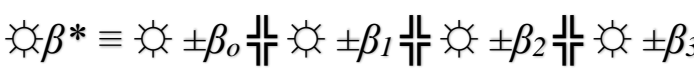

$\left\{\right.$ if $\Delta \mathrm{Y}^{*} \cap \mathrm{R}_{+/-}$then the surface $\equiv$ the coffee market stagnation performance $\}$

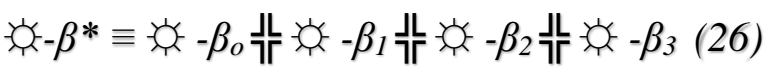

$\left\{\right.$ if $\Delta \beta^{*} \cap R$. then the surface $\equiv$ the coffee market with high vulnerability performance $\}$

\section{How to Calculate the National Coffee Production Function (NCP-Function)}

The application of the National Coffee Production Function (NCP-Function) is divided basically into three basic steps: The first step is to build the national production function by producers, brokers, sellers, and consumers of coffee under the measurement of four subproduction functions. The second step is to compare the same sub-production function of each producer, broker, seller, and consumer of coffee in the same coffee market to find which producer, broker, seller, and consumer of coffee is going to get more benefits on a specific subproduction function. Finally, the third step is to build the NCP-Function through a surface. The NCP-Function is formed by all final national outputs from all producers, brokers, sellers, and consumers of coffee in the same coffee market. It is to monitor the producers, brokers, sellers, and consumers of coffee behaviour. The First step is to try to find the final national output by the NCP-Function, it is depending on measure each sub-production function, each subproduction function is represented by all producers, brokers, sellers, and consumers of coffee respectively (See Expression 7, 8, 9, 10, 11, 12, 13, 14, 15, 16, 17, 18, 19, 20, 21, 22). Finally, the NCP-Function depend on join all four sub-production functions in the common axis sharing 
by the four quadrants of the NCP-Function (Figure 1 and 2). The second step is to compare the same sub-production function by different coffee markets are interested to get a higher benefit based on profits or levels of satisfaction. The second step can help to determinate which sector (producer, broker, seller, and consumer of coffee) is more competitive and better prices (See Expression 23, 24, 25, 26 \& Figure 2 and 3).

Fig. 1. The National Coffee Production Function (NCP-Function) Surface

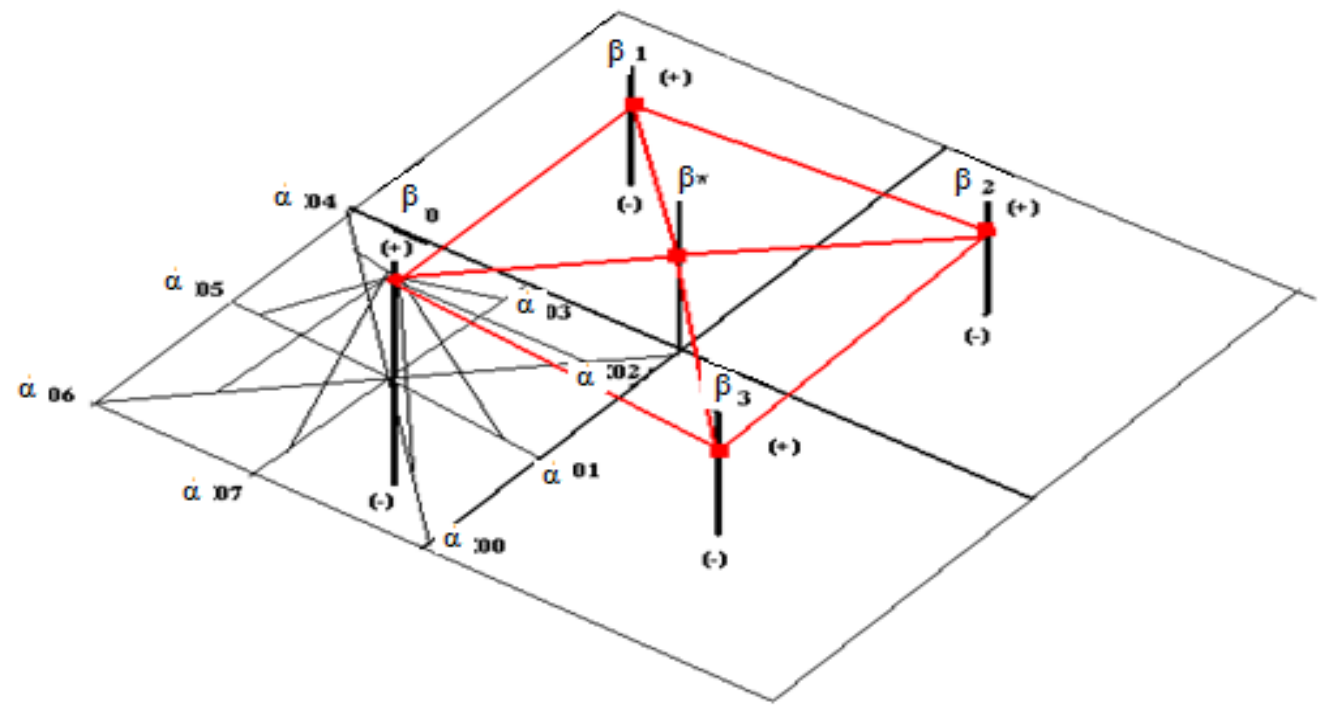

Source: (Ruiz Estrada, 2017)

Fig. 2: NCP-Function Surface by Sub-Production Function

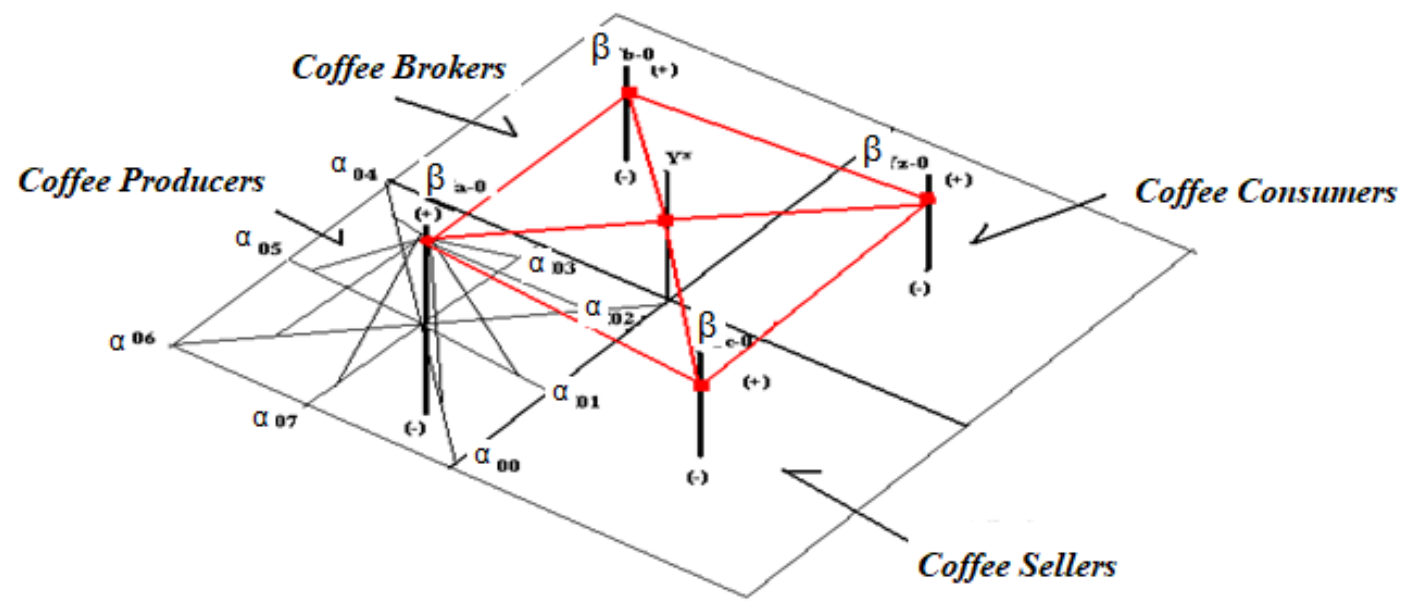


Fig. 3: NCP-Function Surface

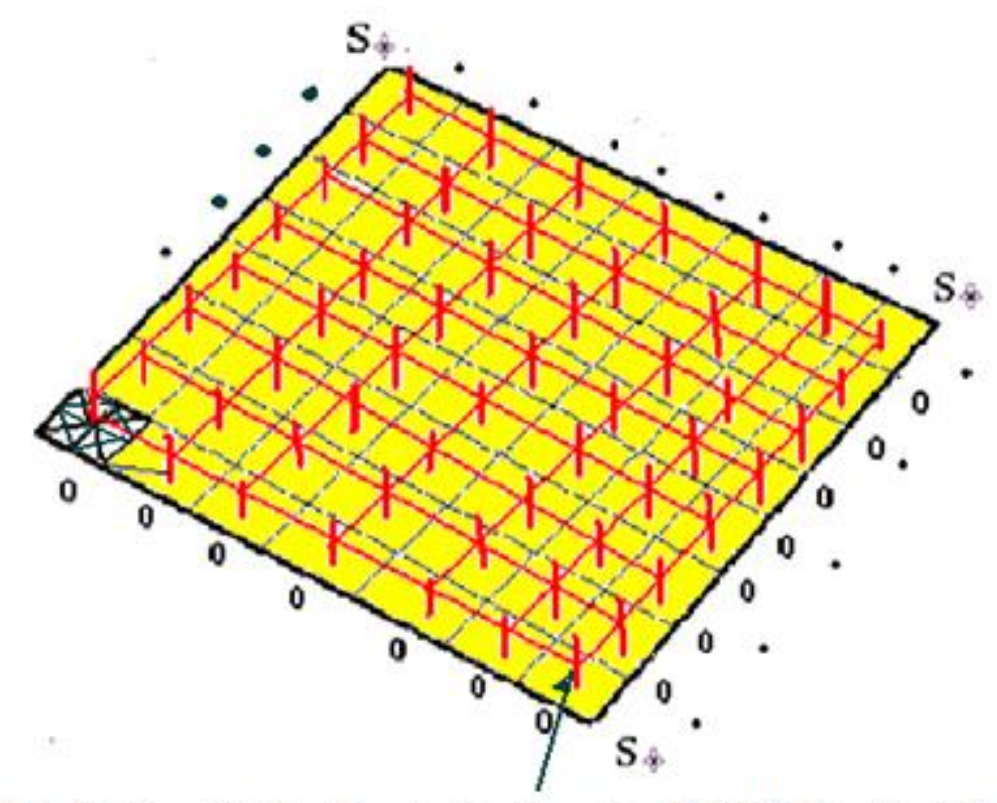

The National Coffee Production Function (NCPF-Function) Surface

Source: (Ruiz Estrada, 2017)

\section{The Application of the National Coffee Production Function (NCP-Function): In the Case of Guatemala}

We examine the national coffee production function (NCP-Function) of Guatemala from 1928 to 2018. We employ secondary data from different database and institutions related to coffee. The NCP-Function is part of what is called cost-benefit analysis. The NCP-Function primarily focuses on the performance and risk of the coffee market structure outcome with regard to a new set of indicators and analytical tools. The NCP-Function is seen as having an important role in supporting the performance of the coffee market structure from four different main players such as producers, brokers, sellers, and consumers (buyers) of coffee. The analysis of the coffee market structure is heavily concentrated on evaluate those four main players as part of the full coffee market structure vulnerability in the short and long run. The full coffee market structure operates within common problems and conditions that share common characteristics: (i) the producer's adversities, (ii) a higher brokers speculation in the coffee market and (iii) the aggressive competition among coffee sellers to extend traditional and potential markets. The NCP-Function vary considerably in the sphere of producers, brokers, sellers and consumers' behaviour in the short and long run. However, they demonstrate a strong linkage from four sub-functions functions.

The NCP-Function for Guatemala is higher with 0.67 between 1928-1958 (see Figure 4). The high rate of NCP-Function is related to Guatemala long trajectory in the production of 
coffee. More specifically, the NCP-Function for Guatemala shows that between 1960-1985 is equal to 0.71 (see Figure 5). Subsequently, the NCP-Function got a higher result of 0.81 between 1985-2005 (See figure 6). Finally, the NCP-Function between 2006-2018 is equal to 0.68 (See figure 7). The last lower result is originated from five main reasons: (i) the strong competition from neighbors such as Costa Rica, Honduras, and El Salvador; (ii) the vulnerability of the coffee prices internationally; (iii) New producers in the international arena from Southeast Asia such as Vietnam and Indonesia; (iv) High speculation from brokers; (v) The fast expansion of large sellers. On the other hand, the missing of international trade with Republic Popular of China from Guatemala government authorities make hard to find potential niches in this large market.

Findings show that the NCP-Function of Guatemala shows that the participation of the total output of coffee in Guatemala among national producers of coffee is equal to $38 \%$ for the large producer, $42 \%$ for cooperatives, and only $12 \%$ for small producers (Villain, Hernández, Anzueto, 2008). Not surprisingly, the Americans and Europeans brokers of coffee as being solely responsible for the high speculation of coffee prices have been replaced by a new mechanism of negotiation and quotation in different levels of producers (large, cooperatives, and small producers). Indeed, observing the role of brokers in the coffee business affects considerably the level of profits among producers followed by large producers (the margin of profit is between $25 \%$ and 35\%), cooperatives (margin of profit is between 18\% and 25\%), and small producers (the margin of profit is between $12 \%$ and $18 \%$ ).

In the case of NCP-Function of Guatemala, the quota of coffee exports to the rest of the world is equal to $65 \%$ of its total national production. This is translated into domestic consumption rate of approximately $35 \%$. In the case of Guatemala coffee market structure is unique due to its good worldwide ranking among the largest coffee producers located in the tenth place for its long history in the coffee international market and quality of coffees from different regions in Guatemala.

The NCP-Function of Guatemala is experiencing fast changes and adaptability according to the fast changes and adaptability to the world coffee market behaviour in the short and long run. The reduction of small producers of coffee directly affects the Guatemalan coffee market structure that is fast moving to large cooperatives for surviving in this competitive coffee market. Despite the fact that the Guatemalan coffee market structure has experienced smaller growth the previous years, the moderate increase NCP-Function of Guatemala is not enough to generate a competitive coffee market structure to compete with large players around the world that can satisfy huge amounts of coffee to large coffee consumers such as Europe and U.S. needs. Similarly, the local consumers of coffee in Guatemala coverage moves in down according to the NCP-Function of Guatemala. Given the coffee producers weak position and high speculation from coffee breakers, the gap between the producers and brokers profits effect considerably the NCP-Function of Guatemala performance in the short and long run. 


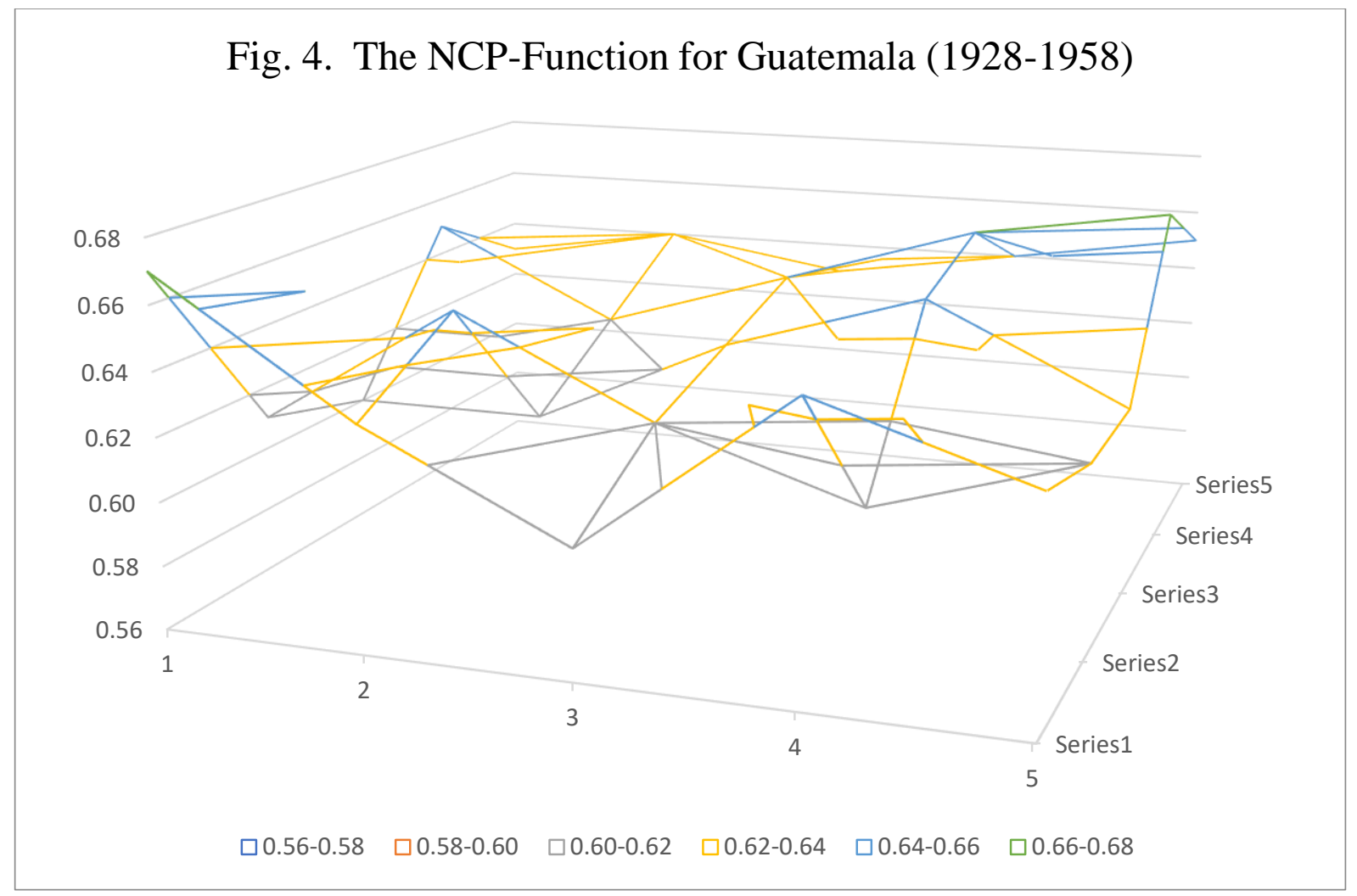

Source: International Coffee Organization (ICO, 2017)

Fig. 5. The NCP-Function for Guatemala (1960-1985)

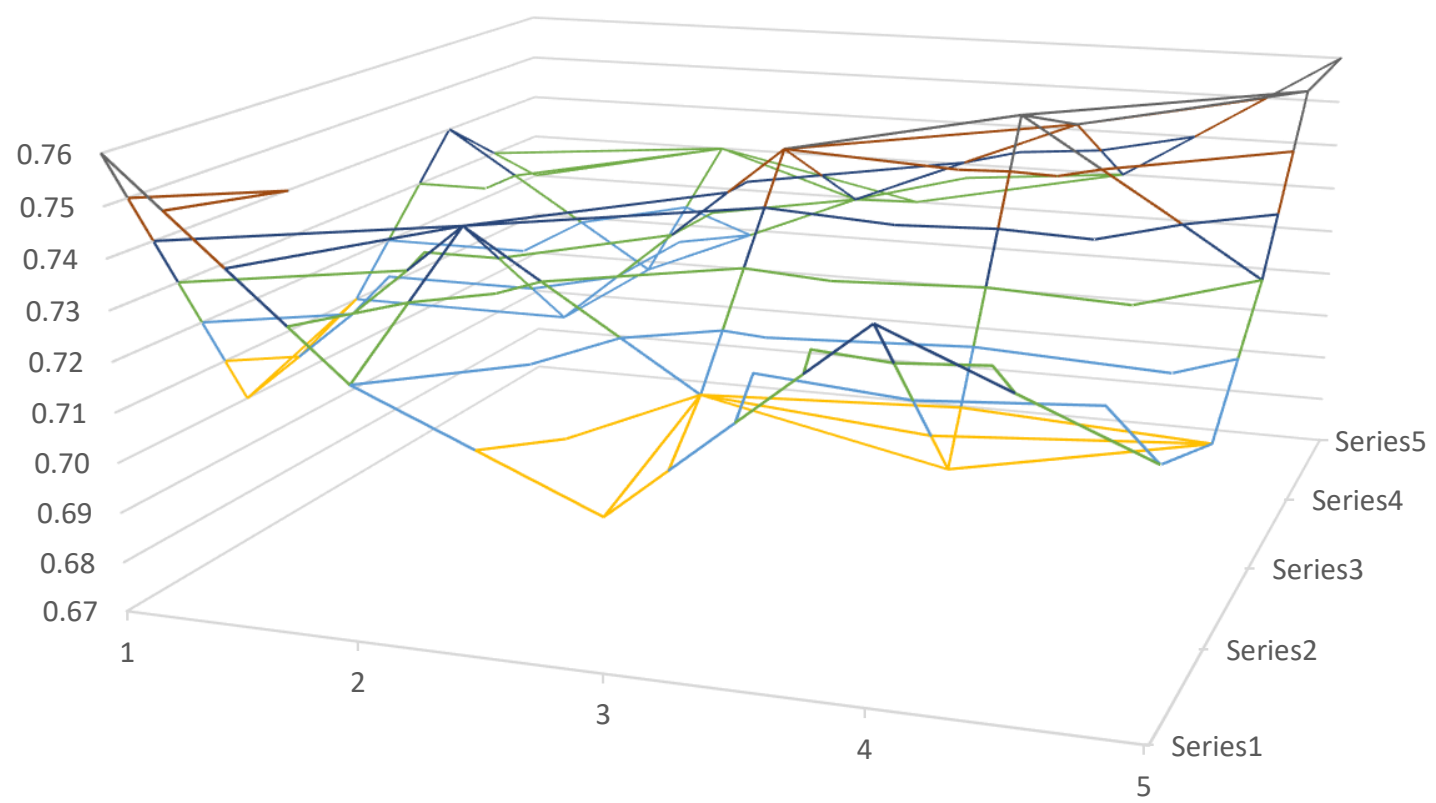

$\square$ 0.67-0.68 $\square$ 0.68-0.69 $\square$ 0.69-0.70 $\square$ 0.70-0.71 $\square 0.71-0.72 \square 0.72-0.73 \square 0.73-0.74 \square 0.74-0.75 \square 0.75-0.76$ 


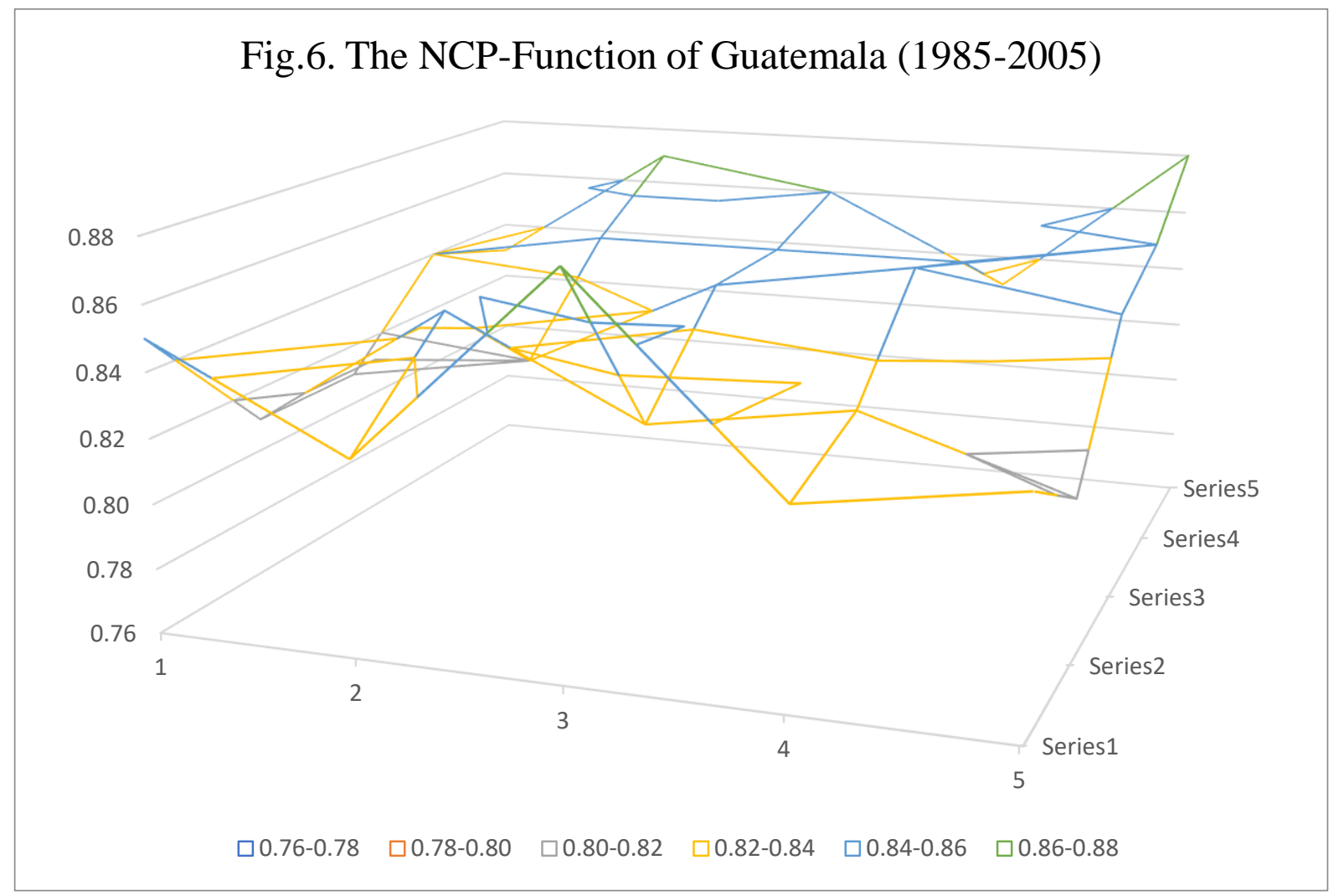

Source: International Coffee Organization (ICO, 2017)

\section{Fig.7. The NCP-Funtion of Guatemala (2006-2018)}

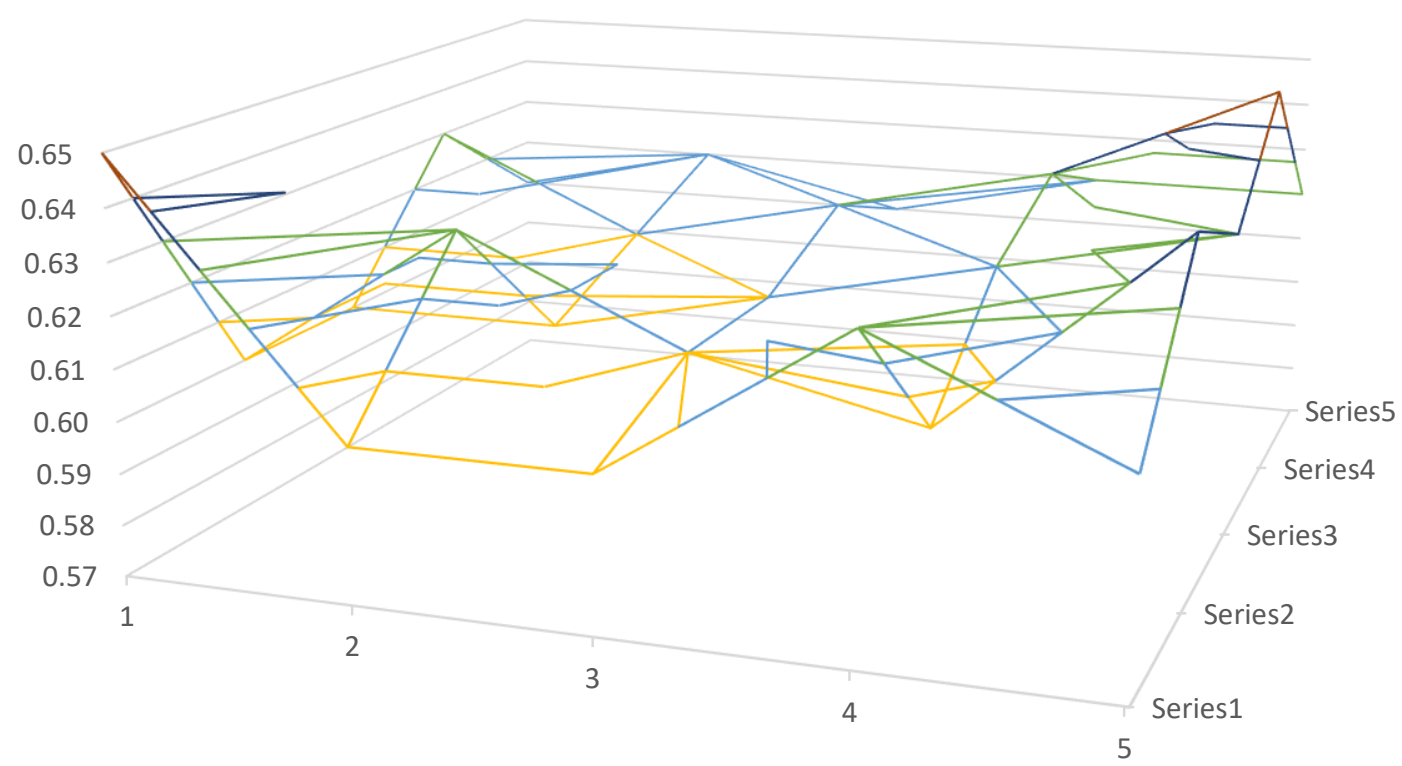

$\square 0.57-0.58 \quad \square 0.58-0.59 \quad \square 0.59-0.60 \quad \square 0.60-0.61 \quad \square 0.61-0.62 \quad \square 0.62-0.63 \quad \square 0.63-0.64 \quad \square 0.64-0.65$ 


\section{Conclusion}

In this paper, we propose a new economics research field, the Coffeeconomics index- a new economic analytical tool used to evaluate the coffee market structure development and progress performance. At the same time, we present a new analytical tools called the national coffee production function (NCP-Function) is based on the use of a set of four sub-functions such as (i) Sub-Function 0: Coffee producers; (ii) Sub-Function 1: Coffee brokers; (iii) Sub-Function 2: Coffee sellers; (iv) Sub-Function 3: Coffee consumers respectively. The underlying intuition is that the coffee market structure depends on the good performance of these four sub-functions keeps a good performance under a lower risk and its productivity faster and homogenously. We hope that the NCP-Function will contribute to a better and more in-depth understanding of measuring the coffee market structure performance as a whole. A more useful measurement of the NCP-Function is conducive in the generation of appropriate policies, both for dealing with the negative factors such as lower productivity, climate change, price discrimination, and constant speculation between producers and brokers of coffee. It is possible with more suitable and realistic planning with better measures which seek to lessen the impact of adverse factors on the coffee market structure collapse before they occur. On the one hand, estimating the negative factors that can affect the coffee market structure may lead to small coffee producers and cooperatives in allocating more efficiently financial and human resources for the generation of a sustainable coffee market structure. At a broader level, our results confirm that a stronger NCP-Function could have a significant impact on the coffee market structure even in small countries producers of coffee. Finally, we conclude that the NCP-Function can offer an alternative graphical and analytical approach in the coffee market structure risk and vulnerability simultaneously.

\section{References}

International Coffee Organization (ICO). A general list of prices. Retrieved from: http://www.ico.org/coffee_prices.asp (2017)

Ruiz Estrada, M.A. (2011). Policy Modeling: Definition, Classification and Evaluation. Journal of Policy Modeling, 33(3): 523-536.

Ruiz Estrada, M.A. and Yap, S.F. (2013). The Origins and Evolution of Policy Modeling. Journal of Policy Modeling, 35 (1): 170-182.

Ruiz Estrada, M.A. 2017. "An Alternative Graphical Modeling for Economics: Econographicology." Quality and Quantity, 51(5):2115-2139.

Ruiz Estrada, M.A., Park, D. 2018. The Past, Present and Future of Policy Modeling. Journal of Policy Modeling, 40(1): 1-15.

Seudieu D.O. (2008) The Coffee Industry: History and Future Perspectives. In: Souza R.M. (eds) Plant-Parasitic Nematodes of Coffee. Springer, Dordrecht

Villain L., Hernández A., Anzueto F. (2008) Central America. In: Souza R.M. (eds) PlantParasitic Nematodes of Coffee. Springer, Dordrecht 
World Trade Organization (WTO). General information. Retrieved from:

https://www.wto.org/english/thewto_e/countries_e/china_e.htm (2018) 